\title{
Quasi-Stationary Planetary Waves in the Southern Hemisphere Troposphere
}

\author{
By Hiromatsu Aoki ${ }^{1}$ and Isamu Hirota \\ Department of Geophysics, Kyoto University, Kyoto 606-8502, Japan \\ (Manuscript received 25 November 1997, in revised form 13 May 1998)
}

\begin{abstract}
By using the NCEP/NCAR Reanalysis dataset for 17 years (1979-1995), the structure and behaviour of quasi-stationary planetary waves (QSPWs) in the Southern Hemisphere winter were studied in relation to the tropospheric zonal wind variations shown by Aoki et al. (1996).

An empirical orthogonal function (EOF) analysis was made of $300 \mathrm{hPa}$ height fields to detect the fluctuation of horizontal QSPW structure. The composite analysis based on the EOF analysis indicated that the QSPWs change their amplitude in the eastern hemisphere and phase in the western hemisphere between the single-jet and double-jet profiles. The wave activity flux diagnosis suggests poleward propagation from the subtropics during the period of single-jet and the equatorward propagation from polar latitudes during the double-jet period.

It is shown that the horizontal EP flux divergence by total waves, especially due to high-frequency disturbances, plays an essential role in the maintenance of the difference between the two jet profiles. As regards the total (horizontal and vertical) divergences, the contribution of the QSPWs to forcing of the zonal-mean zonal wind anomalies is important in higher latitudes around $60^{\circ} \mathrm{S}$.
\end{abstract}

\section{Introduction}

Dramatic change in the zonal wind profile in the stratosphere does not occur in the Southern Hemisphere (SH) winter in contrast to that in the Northern Hemisphere (NH) winter associated with the occurrence of sudden warmings, because the activity of vertically propagating planetary waves is weak in the $\mathrm{SH}$ where the zonal asymmetry at the bottom of the atmosphere is small.

In the SH stratosphere, the core of the westerly jet moves poleward and downward in late winter until the westerlies are replaced by the summer-time easterlies (e.g., Hirota et al., 1983; Shiotani and Hirota, 1985). Shiotani, Shimoda and Hirota (1993) (hereafter refer to as $\mathrm{SSH}$ ) found that this seasonal progression varies from year to year, resulting in substantial interannual variability of the position of the jet in mid-winter in the $\mathrm{SH}$ upper stratosphere. The jet core is at higher (lower) latitudes in mid-winter in the years when the poleward shift of the jet is earlier (later), so that SSH called them high-latitudejet (HLJ) (low-latitude-jet (LLJ)) years. They suggested that tropospheric forcing in autumn is con-

1 Corresponding author: Hiromatsu Aoki, Systems Development Section, Matsushita Information Systems Co., LTD. Shin-osaka Wako Bldg., 6-18, Miyahara 4chome Yodogawaku, Osaka 532-0003, Japan. E-mail: hiromatsu-aoki@tech.mais.mei.co.jp

(C)1998, Meteorological Society of Japan nected with this interannual variability.

Keeping the result of SSH in mind, Aoki, Shiotani and Hirota (1996) (hereafter ASH) investigated the interannual variability of seasonal evolution of the zonal-mean zonal wind in the SH troposphere. They showed that the seasonal march of the latitudinal zonal-mean zonal wind structure can be classified into two types, i.e., double-single (DS) years when a double-jet in early winter changes into a single-jet in late winter and single-double (SD) years when a single-jet in early winter changes into a double-jet in late winter. As was expected, the appearance of SD (DS) years is similar to that of SSH's HLJ (LLJ) years. They also highlighted a close relation between the upward propagation of wavenumber 1 planetary waves into the stratosphere and the tropospheric jet structure, which shows a large seasonality.

The double-jet and single-jet that ASH focused on are thought to be associated with a low-frequency variation dominated in the $\mathrm{SH}$ troposphere (Rogers and van Loon, 1982; Yoden et al., 1987). Mo and White (1985) found that a zonal wavenumber 3 pattern connected with ocean and land distributions is relevant to this low-frequency zonal variation. Yoden et al. (1987) also showed that the single-jet regime is characterized by the large zonal wavenumber 3 amplitude and wavenumber 1 is dominant during the double-jet regime.

Both observational and numerical studies proved 
that eddy momentum flux plays the important role in low-frequency zonal variation rather than eddy heat flux. Karoly (1990) showed that poleward eddy momentum flux is stronger in the double-, rather than single-, jet regime, indicating the significance in sustaining the regimes. Shiotani (1990) exhibited the contribution during the transitions, by showing that poleward (equatorward) eddy momentum flux increases when the zonal wind profile changes from (to) a single- to (from) a double-jet. By using a general circulation model, Yu and Hartmann (1993) studied the role of eddy forcing to show that eddy momentum flux contributes to both the maintenance of the regimes and the transition between the two.

Although these results illustrate the role of "total" waves, the reason why the planetary wave activity changes with the zonal-mean zonal wind profile as observed is not yet clearly explained. It is therefore necessary to examine how particular planetary waves are relevant to the zonal variation, for the purpose of understanding the mechanism of the ASH's and SSH's interannual variabilities. As a first step toward this objective, it is useful to compare the three-dimensional structure of quasi-stationary planetary waves relating to the single-jet structure with what is observed when the double-jet occurs.

\section{Data}

The National Centers for Environmental Prediction (NCEP, formally called the National Meteorological Center (NMC))/National Center for Atmospheric Research (NCAR) Reanalysis dataset was used in this study (see Kalnay et al. (1996) for details of the NCEP/NCAR Reanalysis project and its products). In studying the $\mathrm{SH}$ circulation using this dataset, we must be cautious of the problem of mislocation of $\mathrm{SH}$ surface pressure bogus data from 1979 through 1992. Reports on this problem are available via the Internet (http://wesley.wwb.noaa.gov/paobs/paobs.html).

The impact of this error is largest around $60^{\circ} \mathrm{S}$ and synoptic scale phenomena, such as storm tracks, are most affected. However, the quasi-stationary planetary waves in which we are mostly interested are not expected to be affected significantly because this impact rapidly decreases as altitude, horizontal-scale and time-scale increase.

The original dataset consists of 6-hourly global analyses with $2.5^{\circ}$ longitude-latitude grids on 17 isobaric surfaces (1000-10 hPa) from January 1979 to December 1995. For comparison with ASH's result based on NMC 1200 GMT daily data, only 1200 GMT data of geopotential height $(\mathrm{z})$, temperature $(\mathrm{T})$, zonal and meridional wind $(u$ and $v$, respectively) fields are used in this study. The grid interval is reduced from the original $2.5^{\circ}$ to $5^{\circ}$. We reconfirmed through a preliminary analysis that the

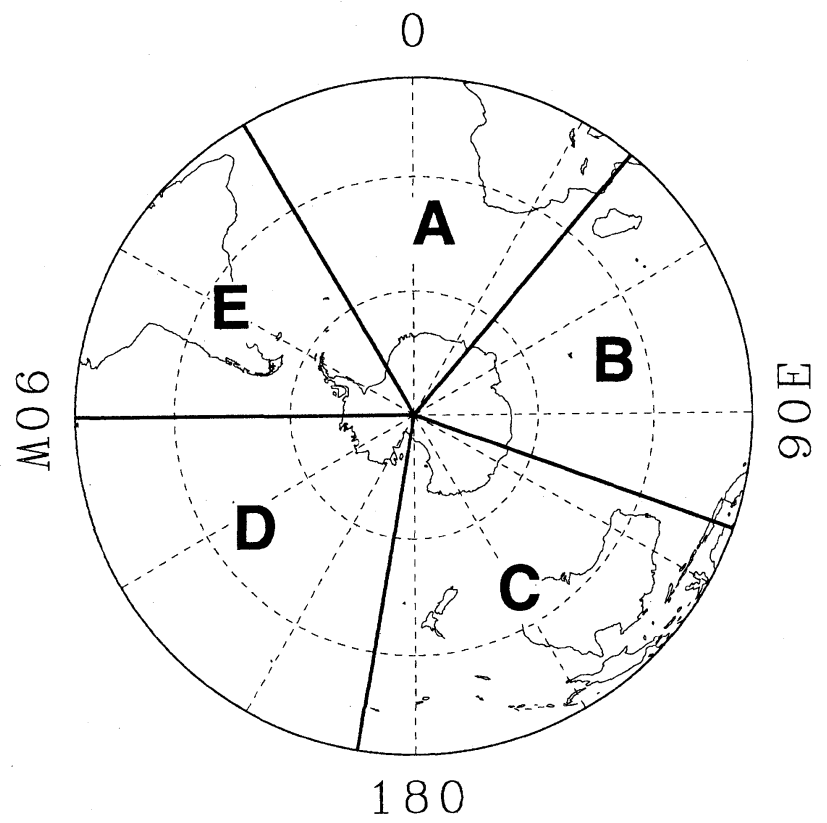

Fig. 1. Rough division of the Southern Hemisphere into five geographical regions, $\mathrm{A}, \mathrm{B}, \mathrm{C}, \mathrm{D}$, and $\mathrm{E}$, corresponding to the Atlantic Ocean-Africa, Indian Ocean, Australia-New Zealand, Pacific Ocean, and South America regions, respectively.

similar results to ASH are obtained even if we use this reduced dataset.

\section{Results}

Because we are interested in the winter circulation in the $\mathrm{SH}$, we make an analysis of the period from April to September. It is well known that a wavenumber 1 planetary wave in the SH stratosphere amplifies in early and late winter with a tendency for minimum amplitude in mid-winter, which is accompanied by the change in westward phase tilt with height (Hirota et al., 1983; Randel, 1988, 1992). In addition, ASH pointed out that the vertical propagation of the wavenumber 1 planetary wave into the lower stratosphere changes qualitatively between early and late winter. Hence, we separate the analysis period into three seasons: early winter (April and May (AM)), mid-winter (June and July (JJ)), and late winter (August and September (AS)). The main focus is placed on the three-dimensional structures of quasi-stationary planetary waves (hereafter abbreviated as QSPWs), which are seen when the single- and double-jet profiles appear for each season. In the following, the rough division into five geographical regions is used, namely, Atlantic OceanAfrica, Indian Ocean, Australia-New Zealand, Pacific Ocean and South America, on the basis of the characteristics of QSPWs and zonal wind. We call these regions $\mathrm{A}, \mathrm{B}, \mathrm{C}, \mathrm{D}$ and $\mathrm{E}$, respectively (Fig. 


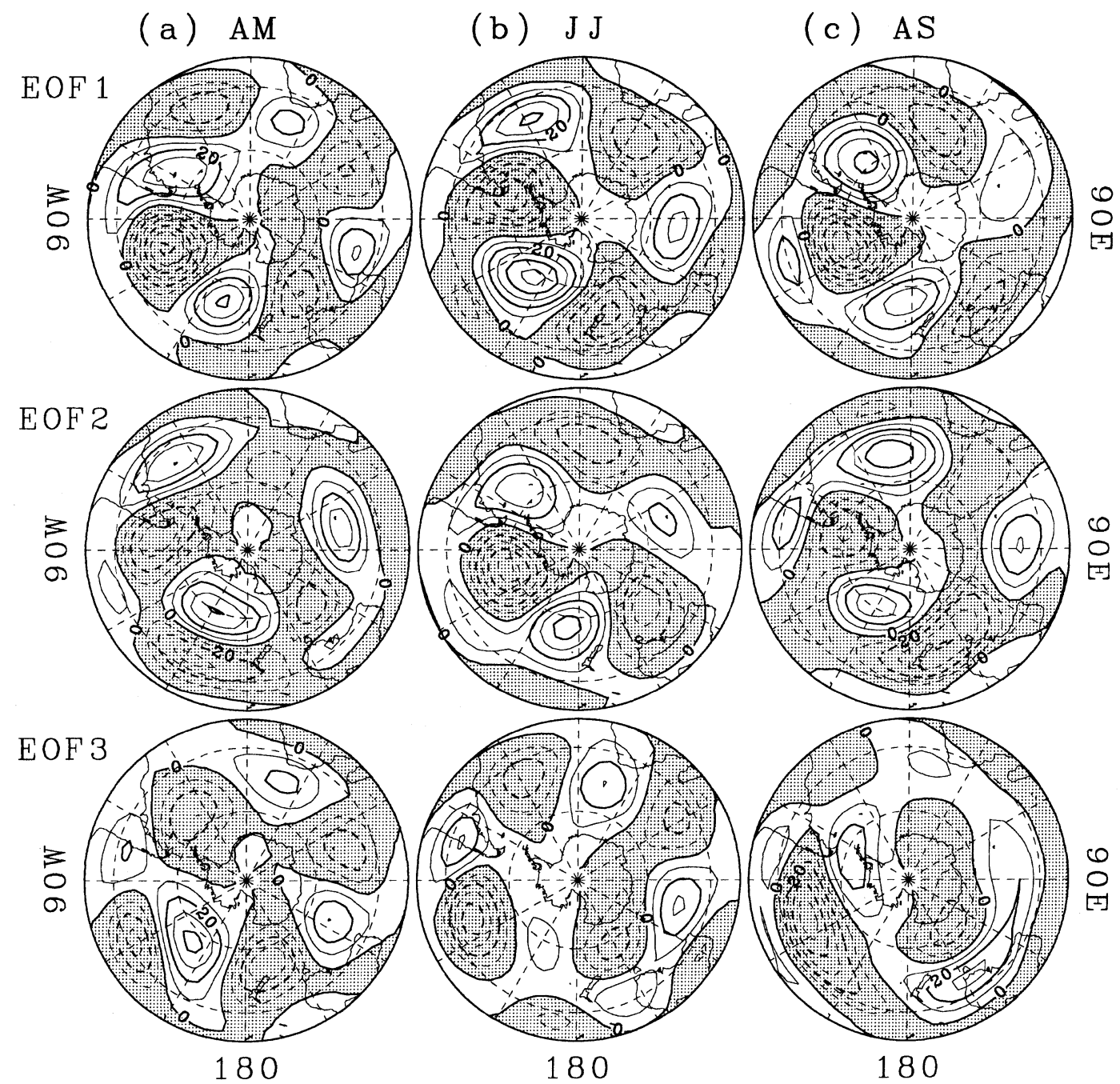

Fig. 2. EOF patterns of the first three principal components (PCs) obtained from 10-day low-pass filtered daily $\mathrm{z}^{*}$ fields at $300 \mathrm{hPa}$ taken from two calendar months over a 17-year interval. (a) for April and May, (b) for June and July, and (c) for August and September. The EOFs are normalized so that the standard deviation of their amplitude equals 1 . The contour interval is 10 and the negative values are shaded. A Lambert equal area projection (poleward from $15^{\circ} \mathrm{S}$ is shown) is used.

1).

\subsection{EOF analysis}

Initial emphasis was put on the horizontal structure of QSPWs at $300 \mathrm{hPa}$ around where the tropospheric height wave amplitude is largest. For each of the three periods, we made an EOF analysis based on the cross-covariance matrix of 10-day low-pass filtered daily $\mathrm{z}^{*}$ fields ( $c f$. Blackmon, 1976), where the asterisk denotes the deviation from the zonal-mean.

The horizontal structures of the first three principal components (PCs) for AM, JJ and AS are displayed in Fig. 2, in which the EOFs are normalized so that the standard deviation of their amplitude equals unity. In AM (Fig. 2a), EOFs 1 and 2 are characterized by wavenumbers 4 and 3 , respectively, and EOF 3 is a mode with wavenumber 4 around $40^{\circ} \mathrm{S}$ and wavenumber 3 in higher latitudes. EOFs
1 and 2 in JJ (Fig. 2b) are the modes with zonal wavenumber 3 , which are in phase quadrature each other, and EOF 3 in JJ has a wavenumber 4 structure. EOFs 1 and 2 in AS (Fig. 2c) roughly correspond to EOFs 2 and 1 in JJ, respectively. EOF 3 in $\mathrm{AS}$ contains the wavenumber 4 similar to EOF 3 in JJ though a wavenumber 1 is more outstanding for AS pattern. Figure 2 suggests that waves with smaller wavenumber become dominant as the season progresses. The cumulative variance of the first three PCs is $36-40 \%$ of the total variance throughout winter (Table 1 ).

North et al. (1982) showed that, if the spacing between a particular eigenvalue and a neighboring one is smaller than their standard errors, separation of the two eigenvalues and eigenvectors will be uncertain, possibly leading to mixing or confusion of the 
Table 1. Fraction of variance, the standard error computed based on North et al. (1982), and the correlation coefficient between the PC and the ZI anomaly for the first five PCs for AM (upper), JJ (middle) and AS (lower).

\begin{tabular}{lrcc}
\hline & $\begin{array}{c}\text { variance } \\
(\%)\end{array}$ & $\begin{array}{c}\text { standard } \\
\text { error (\%) }\end{array}$ & $\begin{array}{c}\text { correlation } \\
\text { coefficinet }\end{array}$ \\
\hline AM PC1 & 14.5 & 0.6 & 0.35 \\
AM PC2 & 11.7 & 0.5 & 0.14 \\
AM PC3 & 10.3 & 0.5 & 0.12 \\
AM PC4 & 8.6 & 0.4 & 0.05 \\
AM PC5 & 7.1 & 0.3 & 0.08 \\
\hline JJ PC1 & 15.5 & 0.7 & -0.02 \\
JJ PC2 & 13.7 & 0.6 & 0.46 \\
JJ PC3 & 7.7 & 0.3 & 0.34 \\
JJ PC4 & 7.2 & 0.3 & 0.01 \\
JJ PC5 & 6.6 & 0.3 & 0.02 \\
\hline AS PC1 & 15.0 & 0.7 & 0.19 \\
AS PC2 & 13.8 & 0.6 & 0.13 \\
AS PC3 & 10.9 & 0.5 & 0.29 \\
AS PC4 & 8.8 & 0.4 & 0.05 \\
AS PC5 & 6.4 & 0.3 & 0.05 \\
\hline
\end{tabular}

patterns. We checked the reliability of our result according to their criterion and found that EOF 3 in JJ and EOFs 1 and 2 in AS did not pass this test (Table 1). As a preliminary analysis, we performed the EOF analysis of $\mathrm{z}^{*}$ fields for 6 -month period from April to September. The horizontal patterns of the PCs 1, 2 and 3 (not shown) all of which pass the North et al. (1982) test are quite similar to those of the PCs 2, 1 and 3 in JJ, respectively. This is also the case for the first two PCs in AS. Therefore, we consider that the main characters of the EOFs in JJ and AS (Figs. 2b and 2c) are qualitatively meaningful even though some of them are not resolved according to North et al. (1982).

Our objective in this study is to compare the characters of planetary wave activity between the high and low ZI extremes. Here, ZI is the ASH's zonal wind index, defined as the difference of the zonalmean zonal wind at $60^{\circ} \mathrm{S}$ and $40^{\circ} \mathrm{S}$. Under this definition, the high (low) ZI corresponds roughly to a double- (single-) jet profile (Figs. 5 and 6 of ASH). In order to pick out the PCs linked to the ZI variation, we computed the correlation coefficients between the amplitude of the PCs and the ZI anomaly for each period (Table 1). (Hereafter, "anomaly" is defined as the deviation from the 17-year-mean for each calendar day.) It is clear that the ZI is not necessarily related to a single mode only. However we consider only PC 1 for AM because its correlation is strikingly high. In JJ, PCs 2 and 3 have significantly high correlation coefficients compared with the other PCs, so that we pay attention to them. In AS, PCs 1 and 3 are relatively highly correlated with ZI anomaly.

It is worth noting that the horizontal structures of PCs we selected are similar to each other between $\mathrm{JJ}$ and AS, as described previously. Moreover, it is quite interesting that the horizontal pattern of $\mathrm{PC} 1$ for AM is similar to that of $\mathrm{PC} 2$ for JJ in the western hemisphere and of PC 3 for JJ in the eastern hemisphere. Therefore, it is expected that the two wave modes (typically represented by PCs 2 and 3 for JJ) are related to the ZI variation throughout winter. The fact that the wave modes with the similar structure are selected for all periods means a high reliability of our result, suggesting that these are dynamically meaningful.

To take the contribution of both of the two PCs for JJ (PCs 2 and 3) and AS (PCs 1 and 3) into consideration, we defined an index as the sum of their amplitudes (hereafter, we call this "PC index"), so that the correlation coefficient between the PC index and the ZI anomaly rises to 0.56 for JJ and 0.34 for AS. Since we are interested in the QSPWs, we defined a positive (negative) event as the period with the positive (negative) PC index lasting more than 20 days. In the following, we construct composites for the fields averaged during an event to make the comparison of the wave activity between the positive and negative extremes of the PC index. (For the case of AM, the PC index is simply the amplitude of PC 1.) The periods used for the composite analysis are listed in Table 2 . Because the PC indices are defined so as to be positively correlated with the ZI anomaly, we call the group with the positive (negative) PC index the high (low) ZI group in the following.

\subsection{Horizontal structure}

Figure 3 exhibits composite maps of $\mathrm{z}^{*}$ at $300 \mathrm{hPa}$. The similarity of behavior is obvious among the three seasons, as expected. The rough structure of QSPWs as seen in the climatology for June or October of Quintanar and Mechoso (1995a) is evident for both groups (Fig. 3 upper and middle panels). A wavenumber 1 is dominant with maximum amplitude around $60^{\circ} \mathrm{S}$ and $30^{\circ} \mathrm{S}$, and wavenumber 3 activity is prominent at mid-latitudes (Trenberth, 1980), so that the ridge around region D splits into two parts. The only exception is the disappearance of wavenumber 3 in the low ZI group in AS (Fig. 3c middle panel).

The location of two ridges (a trough) around the regions D and $\mathrm{E}$ for the high ZI group (Fig. 3 upper panels) corresponds to the trough (ridge) position for the low ZI group (Fig. 3 middle panels). In addition, the trough in region $\mathrm{B}$ deepens and stretches into lower latitudes for the low ZI group. In AM, the difference between the high and low ZI groups (Fig. 3a lower panels) is quite similar to the EOF pattern (Fig. 2a upper panels). This is a zonal wavenumber 
Table 2. Periods used in the composite analysis for the positive (upper) and negative (lower) ZI groups for three periods, April and May (left), June and July (middle) and August and September (right).

\begin{tabular}{|c|c|c|c|c|c|c|}
\hline \multicolumn{3}{|c|}{$\mathrm{AM} \mathrm{PC} 1>0$} & \multicolumn{2}{|c|}{$\mathrm{JJ} \mathrm{PC} 2+\mathrm{PC} 3>0$} & \multicolumn{2}{|c|}{$\mathrm{AS}$ PC1 + PC3 $>0$} \\
\hline Apr & $1-\operatorname{Apr} 29$ & 1979 & Jun 12-Jul 31 & 1979 & Aug 22-Sep 21 & 1979 \\
\hline Apr & 5-May 23 & 1981 & Jun 11-Jul 6 & 1980 & Aug 1-Sep 30 & 1982 \\
\hline Apr & 16-May 31 & 1982 & Jun 11-Jul 31 & 1981 & 2-Sep 25 & 1984 \\
\hline Apr & 1-Apr 28 & 1983 & Jun $1-$ Jul 6 & 1985 & $1-$ Sep 5 & 1987 \\
\hline May & 5-May 31 & 1985 & Jun $1-J u l 29$ & 1986 & Aug 1-Aug 30 & 1989 \\
\hline May & 3-May 31 & 1989 & Jun 10-Jul 9 & 1990 & Aug 30-Sep 22 & 1991 \\
\hline Apr & 1-May 31 & 1995 & Jun $1-J u l ~ 31$ & 1993 & Aug 1-Sep 9 & 1993 \\
\hline \multicolumn{3}{|c|}{$\mathrm{AM} \mathrm{PC} 1<0$} & \multicolumn{2}{|c|}{ JJ PC2 + PC3 $<0$} & \multicolumn{2}{|c|}{$\mathrm{AS} \mathrm{PC} 1+\mathrm{PC} 3<0$} \\
\hline Apr & 1-Apr 26 & 1980 & Jun $27-$ Jul 28 & 1982 & Aug 19-Sep 24 & 1980 \\
\hline Apr & 27-May 31 & 1984 & Jun $1-$ Jul 12 & 1984 & Aug 2-Sep 30 & 1981 \\
\hline Apr & 30-May 19 & 1987 & $8-J u l 28$ & 1987 & Aug 28-Sep 22 & 1983 \\
\hline Apr & 1-May 2 & 1988 & Jul $3-$ Jul 31 & 1991 & Sep 6-Sep 30 & 1987 \\
\hline Apr & 1-May 4 & 1990 & Jun $14-$ Jul 31 & 1992 & Aug $15-$ Sep 30 & 1988 \\
\hline \multirow[t]{2}{*}{ Apr } & 18-May 31 & 1992 & Jun $12-$ Jul 10 & 1994 & Aug $\quad 1-$ Aug 29 & 1991 \\
\hline & & & Jun 17-Jul 31 & 1995 & Aug 20-Sep 30 & 1994 \\
\hline
\end{tabular}

4 but the character such as "meridional" wavetrain pattern of Kidson (1988, his Fig. 4b) is more outstanding. In JJ and AS, the difference (Fig. 3 lower panels) is basically similar to EOF 2 for JJ (Fig. 2b middle panel) and EOF 1 for AS (Fig. 2c upper panel). However some deformations occur by EOF 3 (Fig. 2b lower panel for JJ and Fig. 2c lower panel for AS), especially in the eastern hemisphere. As a result, the difference pattern is similar between AM and JJ.

Figure 4 displays composite maps of zonal wind at $300 \mathrm{hPa}$. Strong jets of over $30 \mathrm{~ms}^{-1}$ are present in two regions, i.e., around $25^{\circ} \mathrm{S}$ between the regions $\mathrm{B}$ and $\mathrm{C}$, and between the region $\mathrm{A}$ (or $\mathrm{E}$ ) around $45^{\circ} \mathrm{S}$ and the region $\mathrm{C}$ (or $\mathrm{B}$ ) around $60^{\circ} \mathrm{S}$. We call the former the "subtropical jet," the latter the "polar jet." The polar jet is weaker in region $\mathrm{E}$ and stronger in region $\mathrm{C}$ for high ZI (Fig. 4 upper panels) than low ZI (Fig. 4 middle panels) group. In region $B$, the polar jet is located at higher latitudes for the high rather than the low ZI group. The zonal-mean structures of zonal winds (Fig. 5) reflect these features. The double-jet (single-jet) profile is obvious for the case of high (low) ZI group throughout winter.

These features of the zonal wind distribution are connected with that of $\mathrm{z}^{*}$ through the geostrophic relation, which is observed most clearly in the difference between the high and low ZI groups. At the poleward (equatorward) side of the positive maxima of the difference of $\mathrm{z}^{*}$ around $50-60^{\circ} \mathrm{S}$ (Fig. 3 lower panels), the difference of zonal wind (Fig. 4 lower panels) is large and positive (negative). In addition, the subtropical jet is stronger (weaker) in the region C (D) for the high rather than the low ZI group.

The difference of the zonal wind between the two groups is larger in the regions D and E in AM (Fig. 4a lower panel) but is larger in the regions $\mathrm{B}$ and $\mathrm{C}$ in AS (Fig. 4c lower panel). External forcing from the subtropics for AM and the coupling with the stratosphere for AS are thought to be the cause of this seasonality, as will be discussed later.

\subsection{Wave activity flux}

We next computed the stationary wave activity flux $\boldsymbol{F}_{s}$ expressed as follows (Plumb, 1985):

$$
\boldsymbol{F}_{s}=\left(F_{\lambda}, F_{\phi}, F_{z}\right)
$$

where

$$
\begin{aligned}
F_{\lambda}=p \cos \phi & {\left[v^{* 2}-\frac{1}{2 \Omega a \sin 2 \phi} \frac{\partial\left(v^{*} \Phi^{*}\right)}{\partial \lambda}\right] } \\
F_{\phi}=p \cos \phi & {\left[-u^{*} v^{*}+\frac{1}{2 \Omega a \sin 2 \phi} \frac{\partial\left(u^{*} \Phi^{*}\right)}{\partial \lambda}\right] } \\
F_{z}=p \cos \phi & \left\{\frac{2 \Omega \sin \phi}{S}\right. \\
& {\left.\left[v^{*} T^{*}-\frac{1}{2 \Omega a \sin 2 \phi} \frac{\partial\left(T^{*} \Phi^{*}\right)}{\partial \lambda}\right]\right\} }
\end{aligned}
$$

Here, $p$ represents the ratio of pressure to surface pressure $(p=$ pressure $/ 1000 \mathrm{hPa}$ ) and $\Omega$ and $a$ stand for angular speed of rotation and radius of the earth, respectively. The parameter $\lambda$ is longitude, $\phi$ denotes latitude, and $\Phi$ indicates geopotential. The static stability, $S$, is defined as

$$
S=\frac{\partial \tilde{T}}{\partial z}+\frac{\kappa \tilde{T}}{H}
$$

where the tilde represents a regional mean (here, averaged between $20^{\circ} \mathrm{S}$ and $\left.90^{\circ} \mathrm{S}\right), \kappa=2 / 7, H$ is the scale height, which is assumed to be constant $(=7000 \mathrm{~m}) . \quad \boldsymbol{F}_{s}$ is an extension of the EliassenPalm (EP) flux and is used for the diagnosis of the 


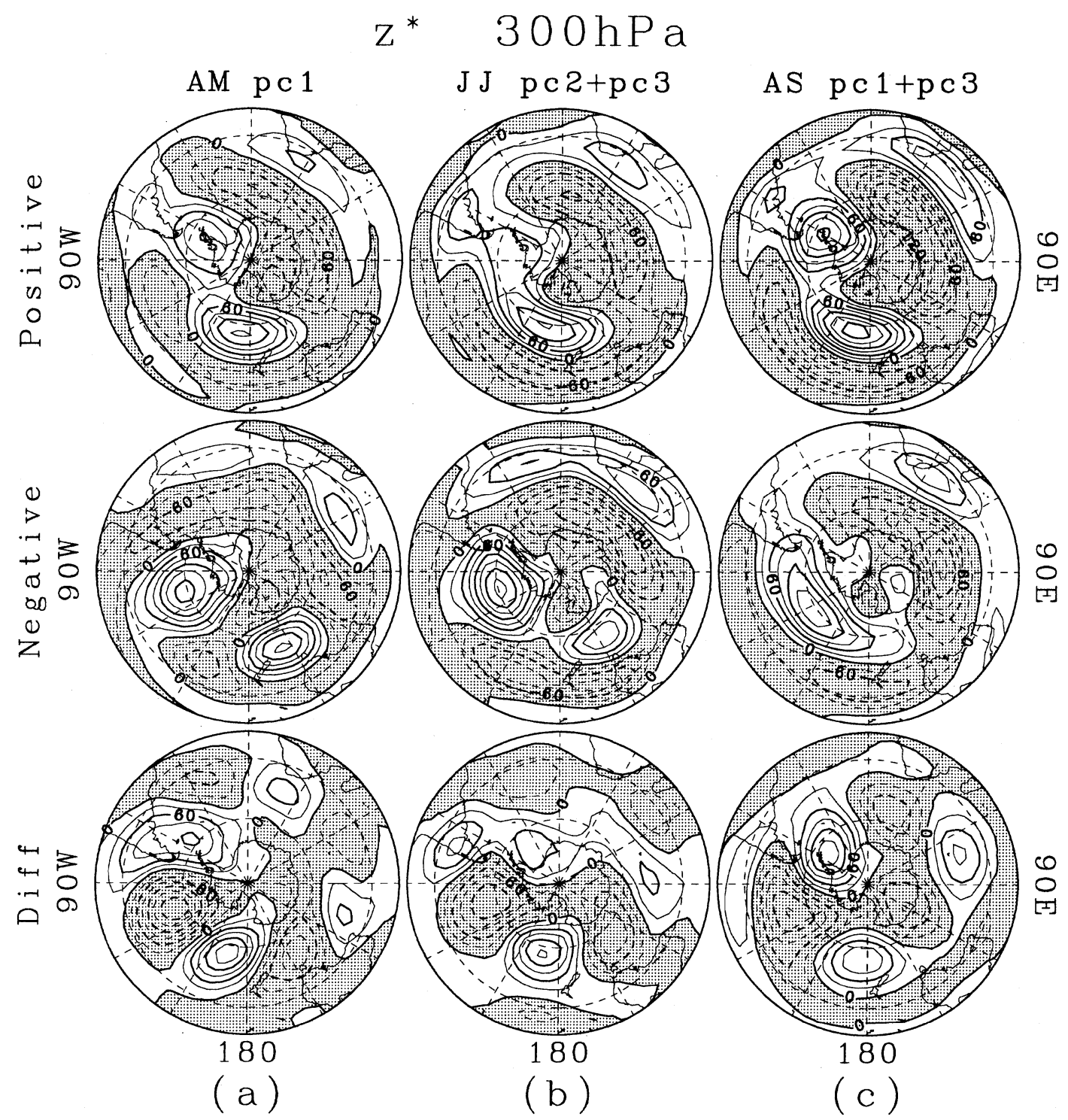

Fig. 3. Synoptic charts of composite $\mathrm{z}^{*}$ at $300 \mathrm{hPa}$ for the group with the positive (upper) and negative (middle) PC index, and the difference between the two (lower) for (a) AM, (b) JJ, and (c) AS. The contour interval is $30 \mathrm{gpm}$ and the negative values are shaded.

three-dimensional propagation of stationary waves. The convergence (divergence) of $\boldsymbol{F}_{s}$ is interpreted as the sink (source) of the wave activity.

Figure 6 shows stationary wave activity fluxes at $300 \mathrm{hPa}$ computed for the composite fields. The horizontal components $\left(F_{\lambda}, F_{\phi}\right)$ are drawn by arrows and the vertical component $F_{z}$ is contoured. There are some discrepancies in detail among the seasons. For example, the vectors point strongly equatorward in AM but slightly poleward in JJ around the region $\mathrm{E}$ for the low ZI group (Fig. 6a middle panel and Fig. $6 \mathrm{~b}$ middle panel). However, agreement in the principal features among the seasons is clear. Strong equatorward fluxes from polar latitudes are evident in the two regions $\mathrm{A}$ and $\mathrm{C}$ for the high $\mathrm{ZI}$ group (Fig. 6 upper panels), which are probably relevant to the wavenumber 1 in the polar latitudes (Fig. 3). For the low ZI group, on the other hand, two intense fluxes are seen from region $\mathrm{B}$ to $\mathrm{C}$ and from region $\mathrm{D}$ to $\mathrm{E}$ (Fig. 6 middle panels), both of which are the manifestation of poleward propagation of wavenumber 3 to $60^{\circ} \mathrm{S}$, and subsequent equatorward motion. A strong upward flux is observed in the regions with strong horizontal flux (in region $\mathrm{C}$ for the high ZI group (Fig. 6 upper panels) and in regions $\mathrm{D}$ and $\mathrm{E}$ for the low ZI group (Fig. 6 middle panels)). It is worth noting that the stronger flux is seen for the low ZI group in AM and JJ but for the high ZI group in AS, although the qualitative natures are unchanged throughout winter for both the low and high ZI group. 

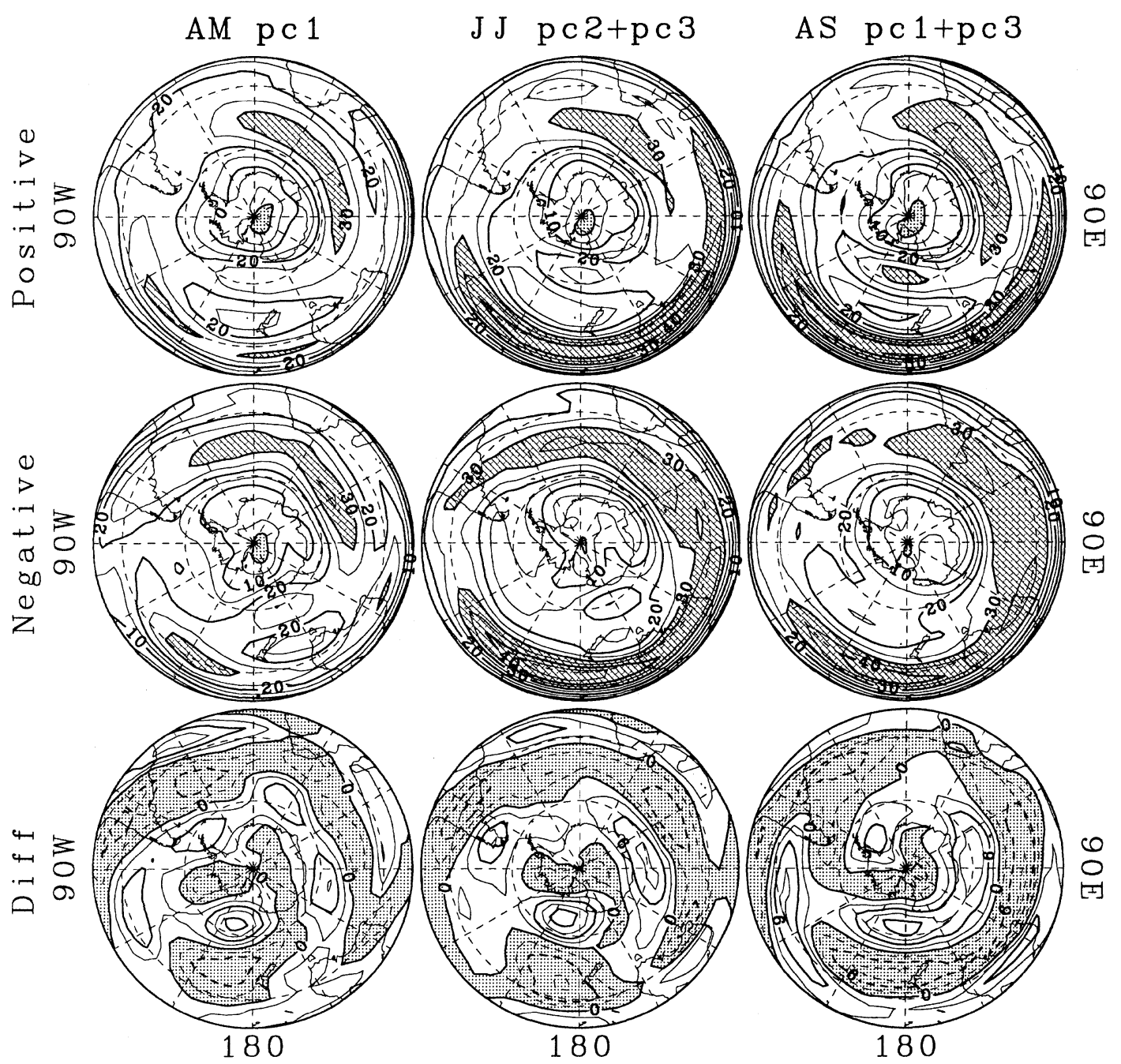

(a)
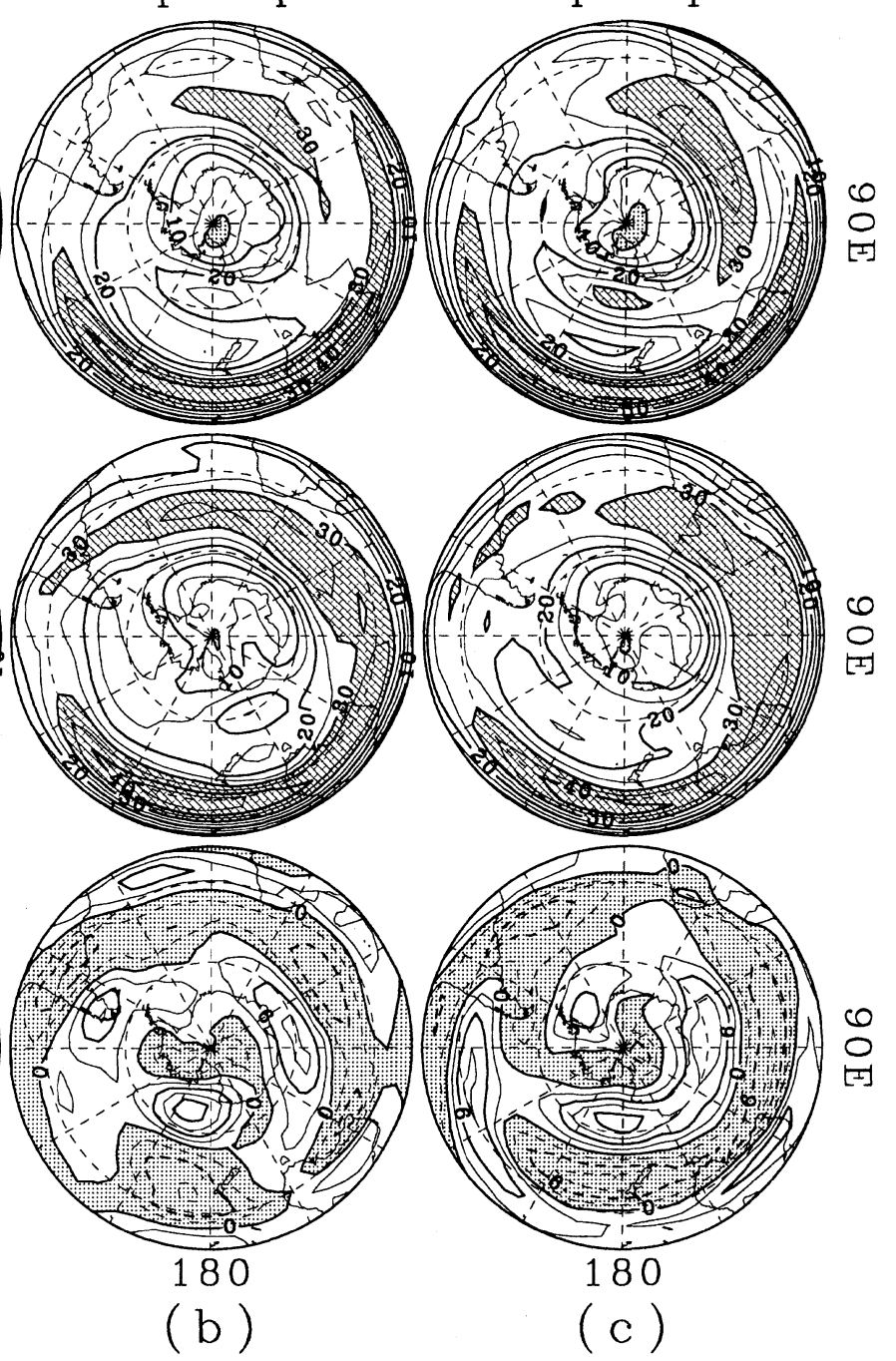

Fig. 4. As Fig. 3 but for the zonal wind. The contour intervals are $5 \mathrm{~m} \mathrm{~s}^{-1}$ (upper and middle panels) and $3 \mathrm{~m} \mathrm{~s}^{-1}$ (lower panels). Regions over $30 \mathrm{~m} \mathrm{~s}^{-1}$ are crosshatched and the negative values are shaded.

Climatologies of stationary wave activity flux in the SH are shown by Karoly et al. (1989) for 10year mean winter (June, July and August) and by Quintanar and Mechoso (1995a) for 12-year monthly-mean fields in February, June and October. Only two of the four intense wave activity fluxes in Fig. 6 are observed in their climatologies, namely, the equatorward flux in the region A (Fig. 6 upper panels) and the flux between the regions $\mathrm{B}$ and $\mathrm{C}$ (Fig. 6 middle panels). There is no evidence of the equatorward propagation around region $\mathrm{C}$ (Fig. 6 upper panels) and the propagation between the regions $\mathrm{D}$ and $\mathrm{E}$ (Fig. 6 middle panels) in their climatologies, which is due to the large interannual phase variation in these regions. In fact, the stationary wave activity flux anomalies for three representa- tive anomaly patterns in the $\mathrm{SH}$ (zonal wavenumber 3, meridional wavetrain, and ENSO patterns, computed by Karoly et al. (1989)) reveal the intense wave activity propagation around region $\mathrm{D}$ (their Fig. 5).

The difference in wave activity flux between the high and low ZI groups is large over nearly the whole hemisphere (Fig. 6 lower panels). This is probably a manifestation of coupling between a zonal wavenumber 3 (and wavenumber 4) and the low-frequency zonal variation. It is, however, worth noting that the stationary wave activity flux anomalies computed for each composite field are similar to what is seen in the meridional wavetrain pattern of Karoly et al. (1989), rather than their zonal wavenumber 3 pattern (not shown). This is most clearly seen in AM, 


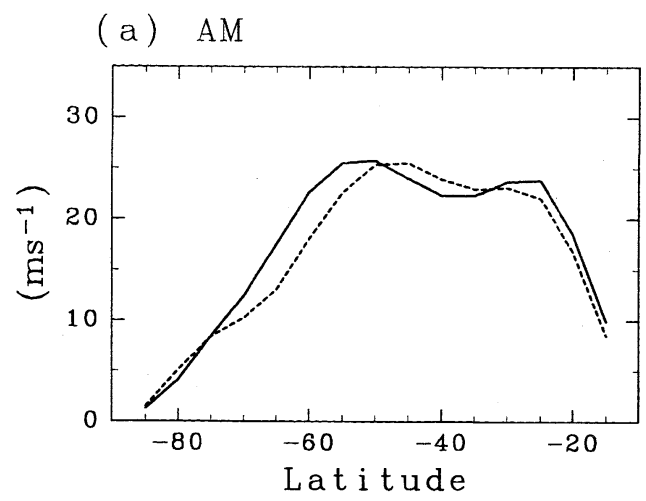

(b ) J J

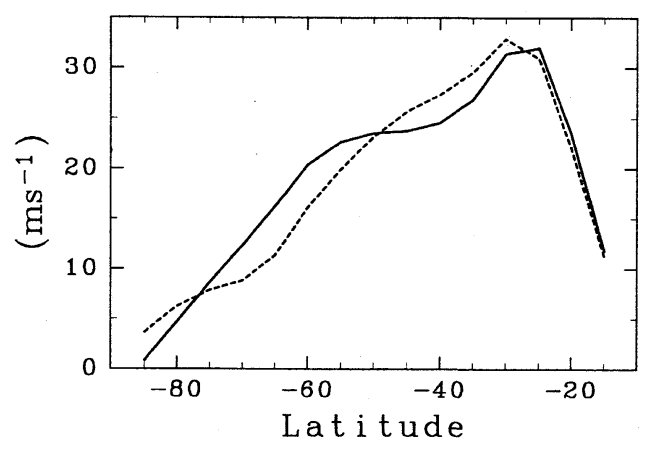

(c) $\mathrm{AS}$

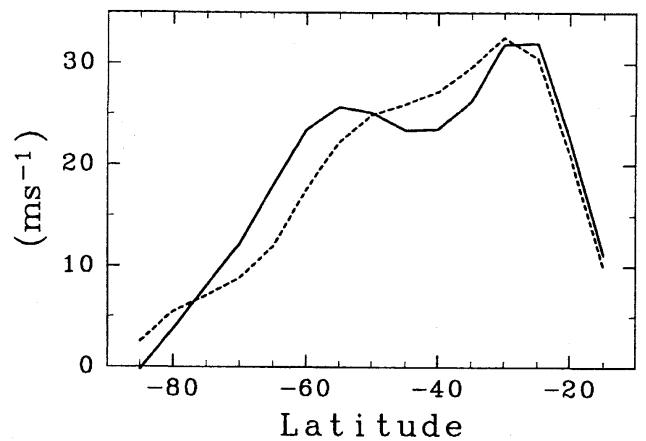

[u ] $\quad 300 \mathrm{hPa}$

high Z I

low Z I

Fig. 5. Latitudinal distributions of composite zonal-mean zonal wind at $300 \mathrm{hPa}$ for the group with the positive (solid curve) and the negative (dotted curve) PC index for (a) AM, (b) JJ, and (c) AS.

as is expected from the EOF pattern (Fig. 2a).

\subsection{Vertical structure}

It is important to investigate the vertical structure of the QSPWs to gain insight into the coupling with the stratosphere. Figure 7 exhibits longitudeheight sections of $\mathrm{z}^{*}$ between $55^{\circ} \mathrm{S}$ and $65^{\circ} \mathrm{S}$, where the maximum amplitude takes place. There is little seasonality of the tropospheric QSPWs, which are basically barotropic. As in Fig. 3, wavenumber 1 is the most dominant component, wavenumber 3 being superimposed on it although wavenumber 3 is weak for the low ZI group in AS. Wavenumber 3 does not propagate upward into the stratosphere and only wavenumber 1 is observed in the stratosphere, though the evidence indicates that wavenumber 3 remains in the lower stratosphere. The phase of $\mathrm{z}^{*}$ tilts westward and its amplitude increases with height in the stratosphere. The temperature waves, $\mathrm{T}^{*}$, which are nearly in phase with $\mathrm{z}^{*}$ in the troposphere, change phase rapidly around the tropopause and are in phase quadrature with $\mathrm{z}^{*}$ in the stratosphere (not shown). The baroclinicity of the QSPWs increases in late winter, resulting in a maximum amplitude in AS in the stratosphere for both of the high and low ZI groups.

The amplitude of stratospheric QSPWs is not distinguishable between the two groups, but it tends to be larger for the high than the low ZI group, espe- cially in JJ (Fig. 7b). The trough in the stratosphere is located eastward for the high ZI group compared with the low ZI group, which can be traced downward into the troposphere for all of the three seasons. Although the stratospheric ridge position is not distinct between the high and low ZI groups, the vertical structure clearly differs.

Longitude-height sections of stationary wave activity flux between $55^{\circ} \mathrm{S}$ and $65^{\circ} \mathrm{S}$ computed for composite fields are shown in Fig. 8. The zonal and vertical components $\left(F_{\lambda}, F_{z}\right)$ are drawn by arrows, and the meridional component $F_{\phi}$ is contoured. The features indicated in Fig. 6 are observed throughout the troposphere. For the high ZI group, there are two strong fluxes around $0^{\circ}$ and $180^{\circ}$, where the propagation of wavenumber 1 from polar latitudes is suggested (Fig. 6 upper panels). For the low ZI group, intense fluxes are obvious at $60^{\circ} \mathrm{E}$ $180^{\circ}$ and $150^{\circ} \mathrm{W}-60^{\circ} \mathrm{W}$, and are expected to have their origin at lower latitudes and to be connected with wavenumber 3 (Fig. 6 middle panels).

It is quite interesting to note that there is a strong seasonality in the vertical propagation of the QSPWs, though the horizontal structure is qualitatively unchanged. The vertical wave activity flux is large in AS in the stratosphere as compared with $\mathrm{AM}$ and JJ, which is linked to strengthening of the baroclinicity in late winter. As regards the regional features, the strength of the wave activity flux in the 


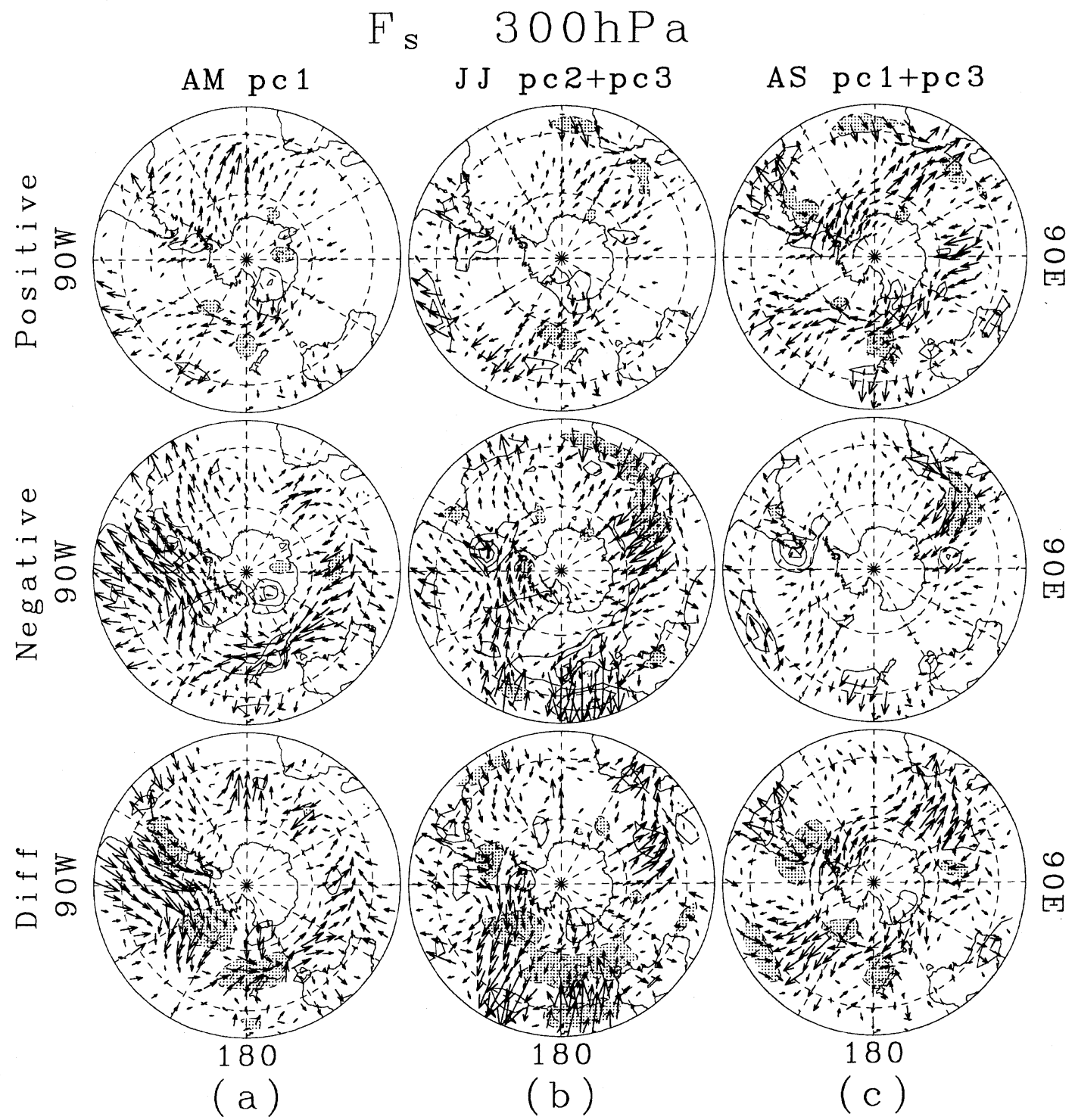

Fig. 6. As Fig. 3 but for the stationary wave activity flux for the composite fields. The horizontal components are drawn by arrows and the vertical component is drawn by contour. A vector length of $5^{\circ}$ in latitude corresponds to about $2 \mathrm{~m}^{2} \mathrm{~s}^{-2}$. Vectors less than $1.2 \mathrm{~m}^{2} \mathrm{~s}^{-2}$ are omitted. The contour interval is $10^{-2} \mathrm{~m}^{2} \mathrm{~s}^{-2}$ and the vales less than $-10^{-2} \mathrm{~m}^{2} \mathrm{~s}^{-2}$ are shaded.

lower stratosphere seems to be dependent on the tropospheric flux in the regions $\mathrm{D}$ and $\mathrm{E}$ for all three seasons. In the regions $\mathrm{B}$ and $\mathrm{C}$, however, the stratospheric planetary wave behavior is somewhat different. The vigorous tropospheric upward flux for the low ZI group decays rapidly around the tropopause, hence the weak stratospheric activity. For the high ZI group, the strong stratospheric wave activity flux manifests only in AS in spite of the weaker upward flux around $500 \mathrm{hPa}$. Interestingly, the seasonality in the regions $\mathrm{B}$ and $\mathrm{C}$ agrees with ASH's result of the vertical EP flux of wavenumber 1.

\subsection{Seasonal evolution}

We next explore the seasonal evolution for each year, in order to discuss the results of ASH. Being highly correlated with the ZI anomaly, the seasonal evolutions of the PC index used in this study are distinct between ASH's DS and SD years, like the ZI anomaly (not shown).

In typical DS years, there is a positive PC index in early and mid-winter but a negative one in late winter. In typical SD years, on the other hand, there is a tendency that the index with a minimum (largest negative value) in early or mid-winter increases with time during mid- and late winter. It is quite interesting that the relatively strong wave activity flux is observed for the low ZI group in AM and JJ and for the high ZI group in AS (Fig. 6). This suggests that SD (DS) years are characterized by the stronger (weaker) wave activity throughout winter 

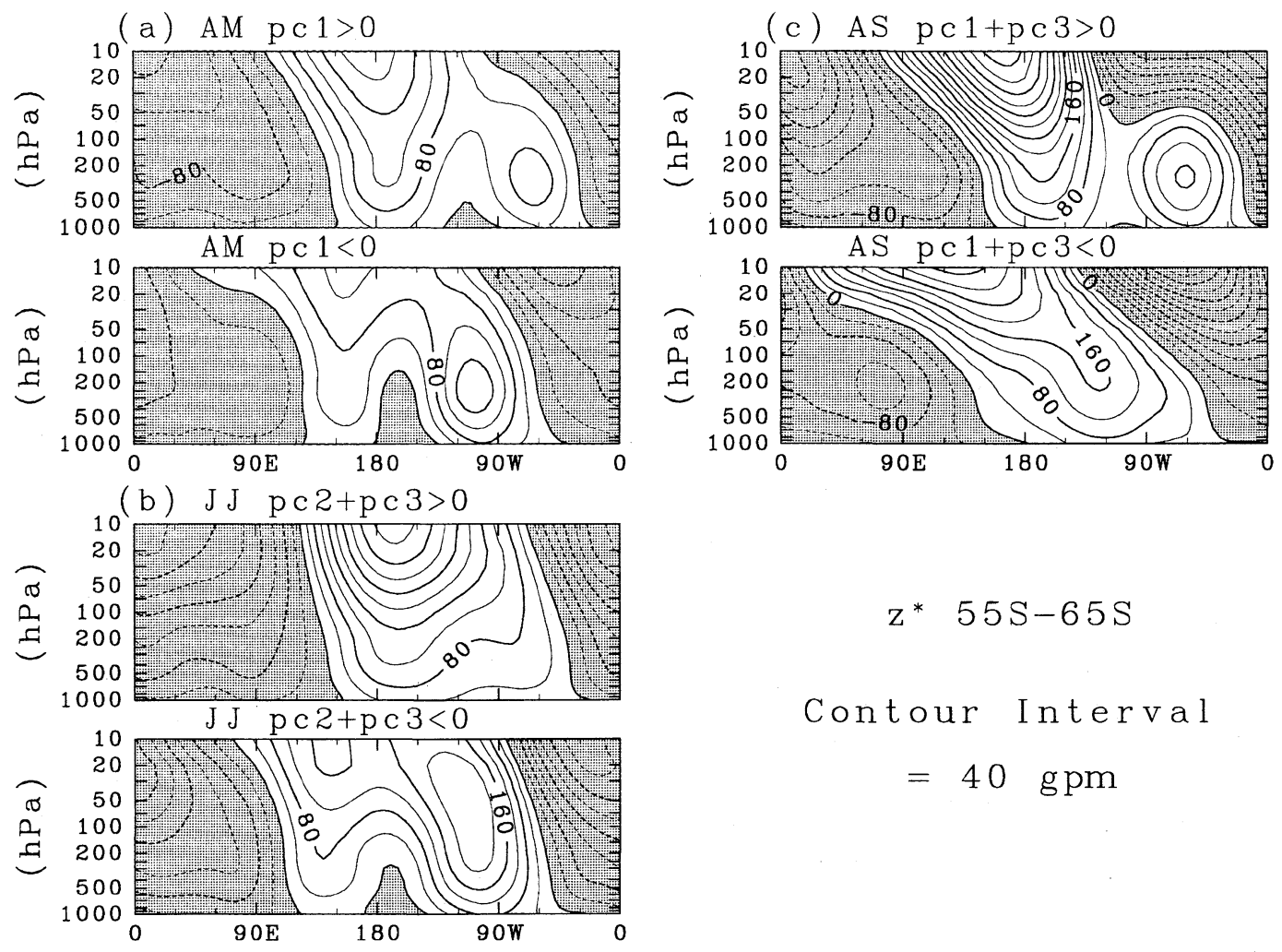

Fig. 7. Longitude-height sections of composite $\mathrm{z}^{*}$ for the group with the positive (upper) and negative (lower) $\mathrm{PC}$ index for (a) AM, (b) JJ, and (c) AS. An average between $55^{\circ} \mathrm{S}$ and $65^{\circ} \mathrm{S}$ is taken. The contour interval is $40 \mathrm{gpm}$ and negative values are shaded.

(May-September). As seen in Fig. 2, EOF patterns are dominated by wavenumbers 3 and 4 in AM and JJ. For AS, the EOFs 1 and 2 have also wavenumber 3 structure, but wavenumber 1 is outstanding for the EOF 3. The seasonality of these EOF patterns is probably related to that of the wave activity flux. The wave activity flux in the stratosphere (Fig. 8) is also stronger for AM and JJ but weaker for AS in the negative than the positive ZI group as seen for the horizontal flux in the troposphere (Fig. 6).

\section{Discussion}

\subsection{Wavenumber 3 pattern}

As shown by the earlier studies, the zonal wavenumber 3 is related to the $\mathrm{ZI}$ variation. In addition to the change in the wave amplitude, we found the phase change in the western hemisphere (Fig. 3 ), which has not been so far documented in connection with the $\mathrm{ZI}$ variation. The main features of the horizontal structures of QSPWs associated with the high and low ZI are schematically displayed in Fig. 9 and summarized as follows:

- In region $B$, the trough is deeper and extends into lower latitudes, and accompanies the changes in the polar jet position into the lower latitude, for the low rather than high ZI group.
- In the regions $\mathrm{D}$ and $\mathrm{E}$, there is an out-of-phase relation of the QSPWs between the two groups. The polar jet is stronger around region $\mathrm{C}$ and weaker in region $\mathrm{E}$ for the high rather than the low ZI group. The subtropical jet is stronger (weaker) around region C (D) for the high than low ZI group.

- The wave activity flux suggests equatorward propagation from polar latitudes in regions A and $\mathrm{C}$ for the high $\mathrm{ZI}$ group. For the low ZI group, the wave activity in the subtropical source regions $\mathrm{B}$ and $\mathrm{D}$ propagates poleward to about $60^{\circ} \mathrm{S}$, and then equatorward in the regions $\mathrm{C}$ and $\mathrm{E}$, respectively.

The horizontal structure of EOF 1 in AM (Fig. 2) bears a strong resemblance to the "meridional" wavetrain pattern of Kidson (1988). It is inferred from a calculation of the wave activity flux anomalies (Karoly et al., 1989) that the meridional wavetrain pattern is associated with forcing in the subtropics around region $\mathrm{D}$ (and/or C). This suggests that there is a possibility that the variation of QSPWs studied in this study is linked to the phenomena in the lower latitudes, such as the variation of sea surface temperature in the subtropics. 

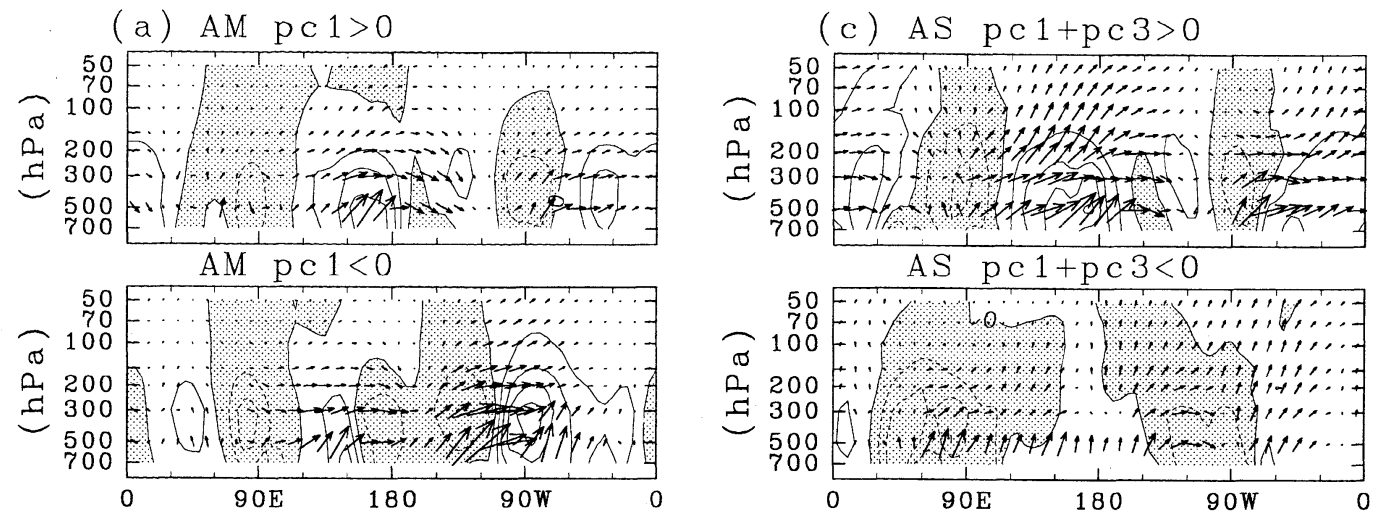

(b) J J pc2+pc3>0

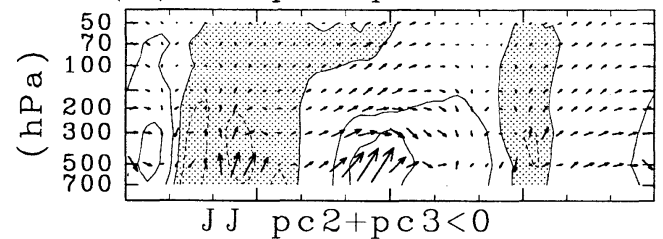

$F_{s} 55 S-65 S$
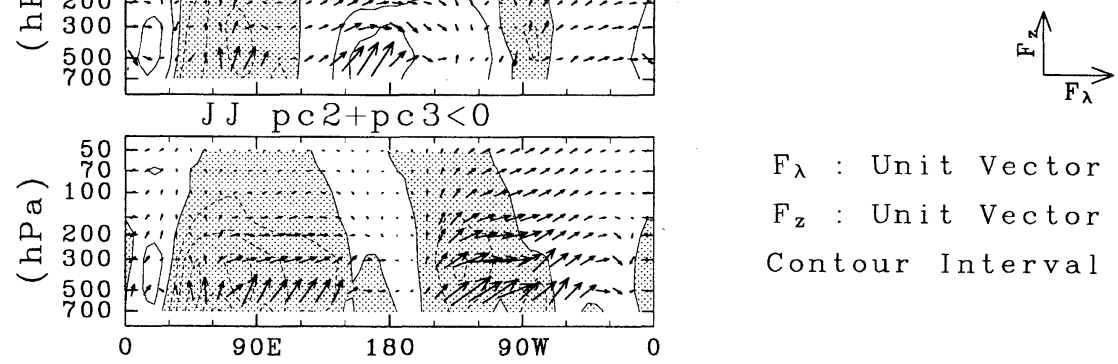

$$
\begin{aligned}
& F_{\lambda} \text { : Unit Vector }=5.00 \mathrm{~m}^{2} \mathrm{~s}^{-2} \\
& \mathrm{~F}_{\mathrm{z}} \text { : Unit Vector }=0.02 \mathrm{~m}^{2} \mathrm{~s}^{-2} \\
& \text { Contour Interval }=1.00 \mathrm{~m}^{2} \mathrm{~s}^{-2}
\end{aligned}
$$

Fig. 8. As Fig. 7 but for the stationary wave activity flux for the composite monthly-mean fields between 700 and $50 \mathrm{hPa}$. The zonal and vertical components are drawn by arrows and the meridional component is drawn by contour.
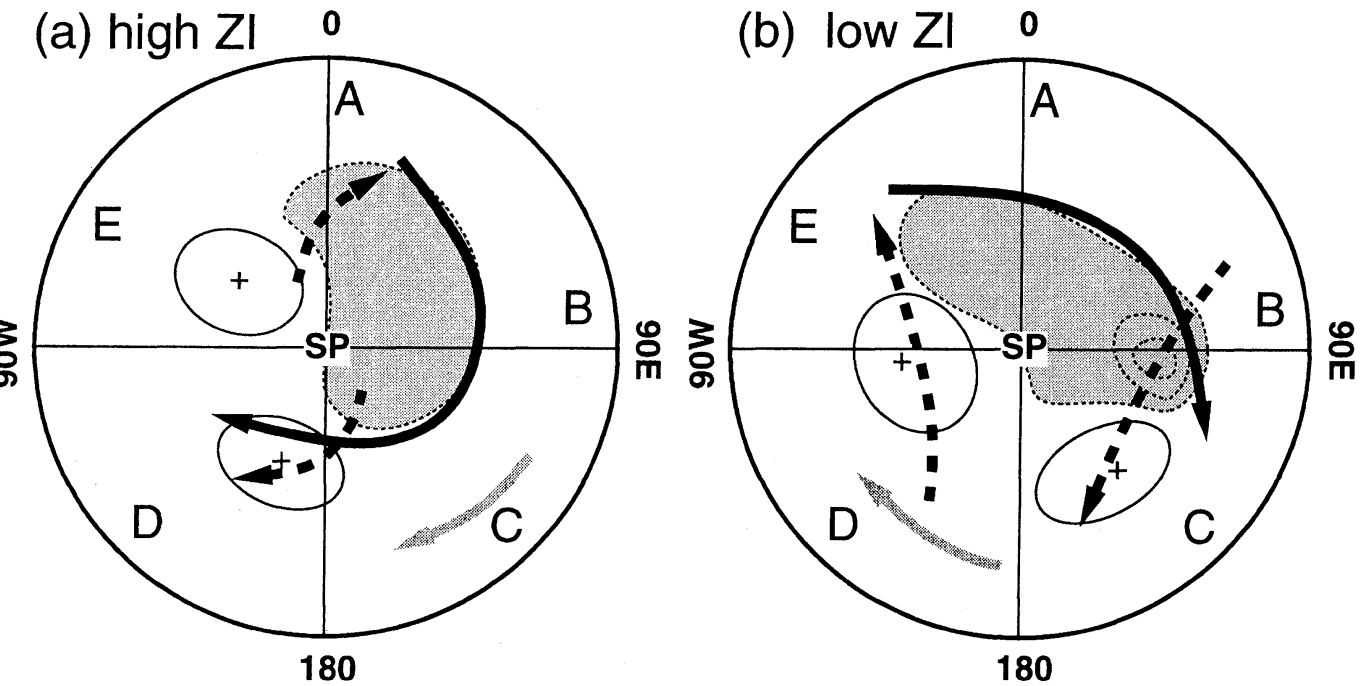

Fig. 9. Schematic synoptic charts that explain the characteristics of quasi-stationary planetary waves and zonal wind relating to (a) the high ZI and (b) the low ZI. Plus signs denote the ridge positions and the shaded region represents the trough. A dark solid arrow indicates the (strong) polar jet and a light arrow stands for the location of stronger subtropical jet. Dotted arrows indicate the direction of horizontal propagation of quasi-stationary waves. A, B, C, D, and E correspond to Atlantic Ocean-Africa, Indian Ocean, Australia-New Zealand, Pacific Ocean, and South America regions, respectively. 
(a) $\mathrm{AM}$

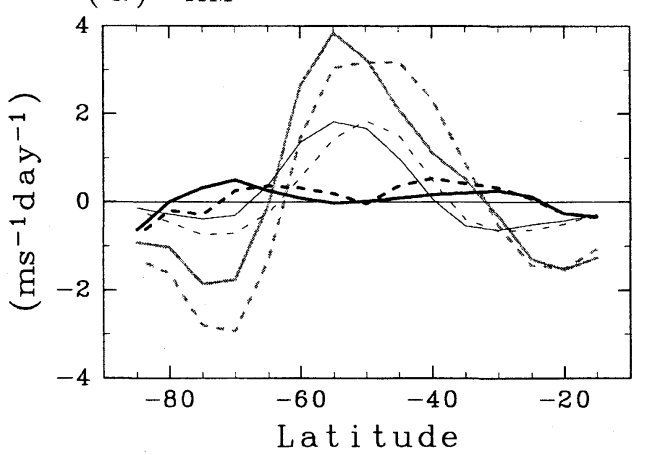

(b ) J J

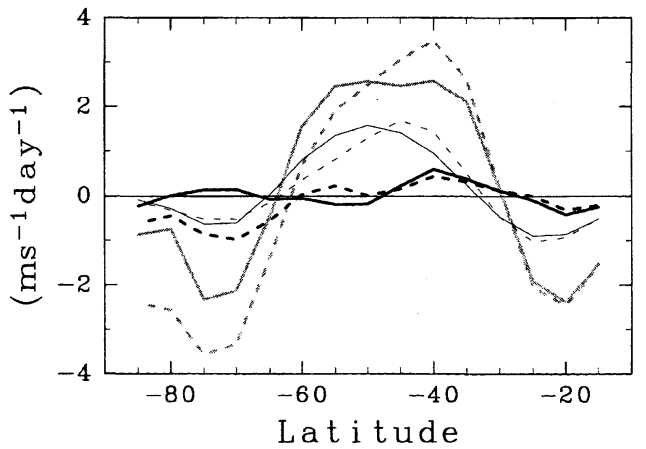

(c) AS

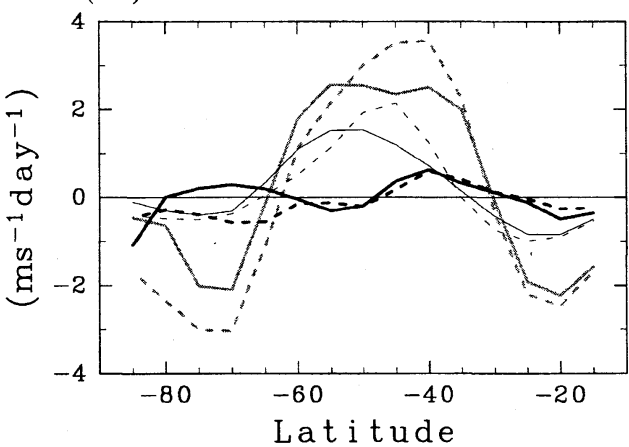

$\mathrm{F}_{\varphi \varphi} 300 \mathrm{hPa}$

Total

Low freq

$\mathrm{High}$ freq

Fig. 10. Latitudinal distributions of composite horizontal divergence of EP flux (wave forcing) for the group with the positive (solid curve) and the negative (dotted curve) PC index for (a) AM, (b) JJ, and (c) AS. Dark thick and thin curves denote the forcing by quasi-stationary waves and high-frequency disturbances, respectively. Light curves stand for the contribution of total waves including both quasi-stationary and high-frequency eddies.
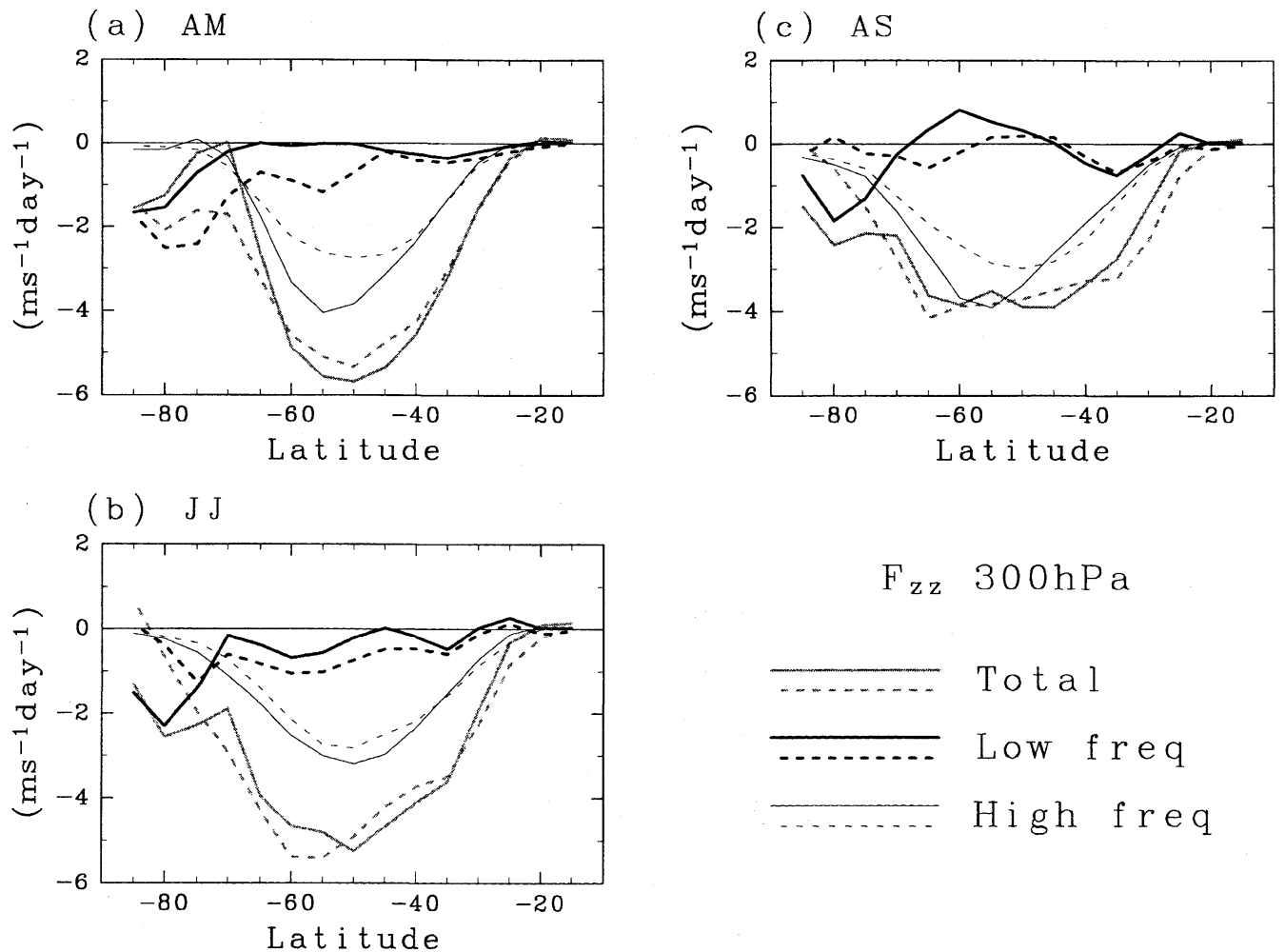

$\mathrm{F}_{\mathrm{zz}} 300 \mathrm{hPa}$
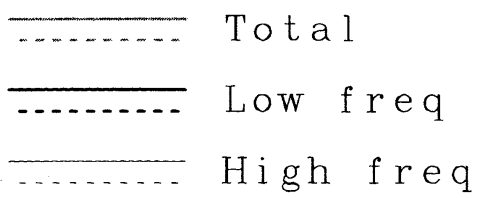

Fig. 11. As Fig. 10 but for vertical divergence. 
The forcing mechanism of planetary waves in the SH troposphere has been studied by using numerical models (James, 1988; Watterson and James, 1992; Quintanar and Mechoso, 1995b). It is impossible, however, to relate their results directly to ours because these authors concentrated on the climatological nature of forced Rossby waves. It will be interesting to compare the wave structures generated by various forcings when the double-jet appears with what is seen relating to the single-jet, using a numerical experiment.

\subsection{Zonal forcing}

To study how the QSPWs act on the zonal-mean zonal wind, we compute the EP flux divergence. The horizontal and vertical EP flux divergences are shown in Fig. 10 and 11, respectively. For comparison, the divergences for high-frequency disturbances (6-day high-pass filtered fields) and total waves (daily fields) are also shown. Qualitatively, there is no seasonality again, although a quantitative inconsistency is seen among the seasons for both components. The total waves force the zonal-mean zonal wind to accelerate in mid-latitudes and to decelerate in the subtropics and high latitudes through horizontal divergence and to decelerate through vertical divergence. However the contribution of QSPWs is generally small.

The difference between the high and low ZI groups explains how the waves act on the zonal-mean zonal wind. The zonal-mean zonal wind is stronger (weaker) around $60^{\circ} \mathrm{S}\left(40^{\circ} \mathrm{S}\right)$ for high rather than low ZI (Fig. 5). If the divergence shows the similar (opposite) natures, the waves act to increase (decrease) the zonal wind anomaly. The horizontal divergence by the QSPWs is weak and the difference between the two groups is small (Fig. 10), indicating that it is irrelevant to the ZI variation. This is in marked contrast to the substantial role of the total waves, which is mainly due to high-frequency disturbances, in the maintenance of the single- or doublejet profile. The vertical divergence is higher for the QSPWs but lower for high-frequency disturbances around $50-70^{\circ} \mathrm{S}$ in the high than low ZI group, so that the forcing by the "total" vertical divergence is not significant (Fig. 11).

As for the high-frequency disturbances, the horizontal driving force of the zonal-mean zonal wind anomaly around $60^{\circ} \mathrm{S}$ (Fig. 10) is compensated by an opposite forcing weakening the anomaly from the vertical divergence (Fig. 11). For this reason, the contribution of total forcing (the sum of the horizontal and vertical divergences) by the QSPWs can not be ignored.

From these results, we conclude that the horizontal structure of QSPWs plays little role but that the vertical structure around $60^{\circ} \mathrm{S}$ is important in maintaining the two jet structures. This implies that

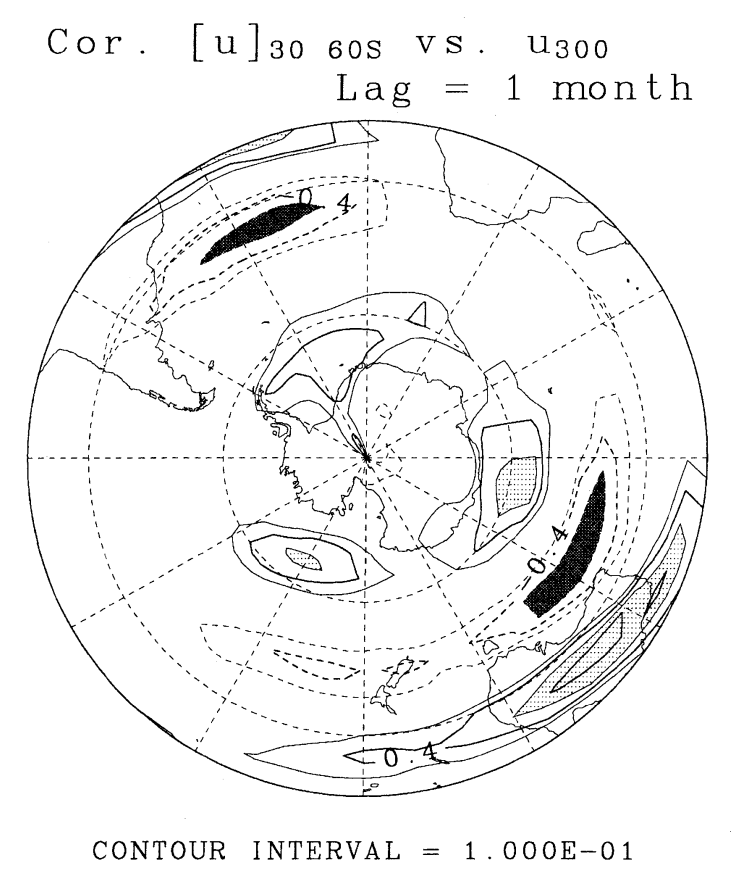

Fig. 12. Synoptic chart of correlation coefficient at one-month lag between the monthly-mean zonal wind at $300 \mathrm{hPa}\left(u_{300}\right)$ and the monthly-mean zonal-mean zonal wind at $30 \mathrm{hPa}$ at $60^{\circ} \mathrm{S}$ $\left([u]_{30}\right)$. The correlation coefficients between $u_{300}$ in August and $[u]_{30}$ in July and between $u_{300}$ in September and $[u]_{30}$ in August are averaged. The contour interval is 0.1 and values between -0.2 and 0.2 are not contoured. Light and dark shading corresponds to values over 0.5 and under -0.5 .

we are still unable to explain why the horizontal structure of QSPWs must be different between the two groups. However a clear difference is seen (Fig. 3 ). What causes the change in the horizontal wave structure? This may be partly explained in terms of the refractive index such that the horizontal wave propagation is modified by a change in the zonal wind, leading to a change in the horizontal structure as schematically illustrated in Fig. 9. A simple interpretation from this viewpoint is given in the Appendix, and further analysis is needed for a complete understanding, together with consideration of the forcing mechanism.

\subsection{Coupling with the stratosphere}

ASH pointed out that the upward wavenumber 1 EP flux in the lower stratosphere in late winter is strong when the double-jet appears in spite of the weak flux in the troposphere. They used the following reasoning to explain this: In the years when the polar-night jet shifts poleward and downward earlier (SSH's HLJ years), the influence reaches down into the troposphere and the westerlies around $60^{\circ} \mathrm{S}$ 


\section{$300 h P a$ September}
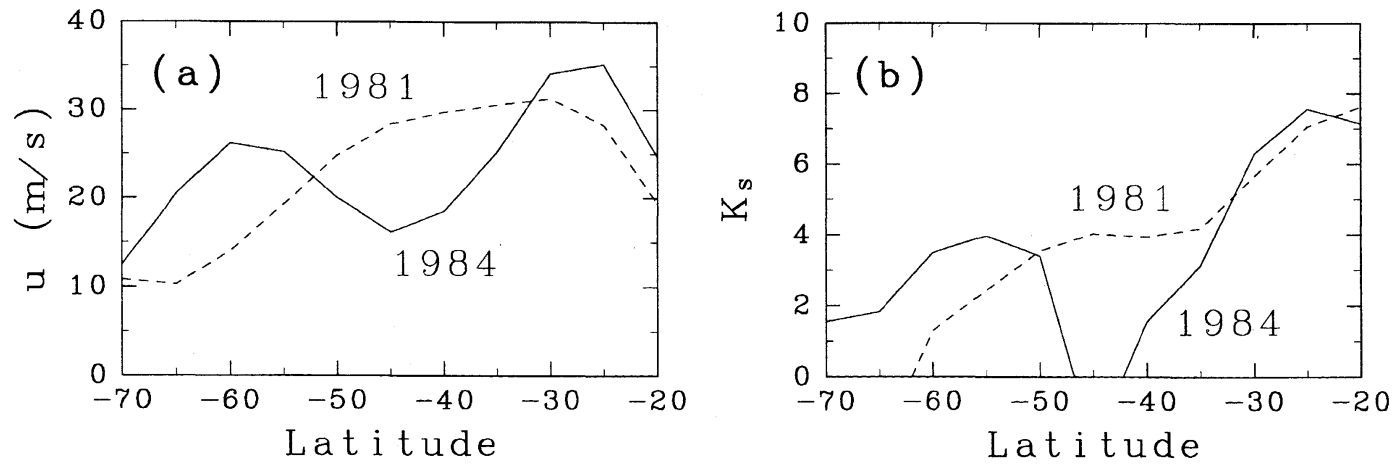

Fig. 13. Latitudinal distributions of (a) monthly-mean zonal-mean zonal wind and (b) the corresponding total steady wavenumber $K_{s}$ at $300 \mathrm{hPa}$ in September in 1981 (dotted curve) and 1984 (solid curve).

become strong, resulting in a double-jet structure in late winter (ASH's SD years). These strong westerlies act as a waveguide, in which wavenumber 1 planetary waves propagate efficiently into the stratosphere in spite of the weaker tropospheric activity.

We checked whether consistent results follow from their scenario by computing the correlation coefficients between the polar-night jet strength and the tropospheric zonal wind. High values are obtained for the correlation with a lag rather than for the simultaneous correlation. This is displayed in Fig. 12 , which shows a correlation map at one-month lag between zonal-mean zonal wind at $30 \mathrm{hPa}$ at $60^{\circ} \mathrm{S}$ $\left([u]_{30}\right)$ and zonal wind at $300 \mathrm{hPa}\left(u_{300}\right)$. The correlation coefficients between $[u]_{30}$ in July and $u_{300}$ in August and between $[u]_{30}$ in August and $u_{300}$ in September are averaged.

The correlation is high in the regions $\mathrm{B}$ and $\mathrm{C}$, which suggests that in the years when $[u]_{30}$ is strong (weak) in mid-winter (July and August), the character of high (low) ZI is clearly seen in the regions B and $\mathrm{C}$ in the subsequent month. Interestingly, the horizontal pattern is similar between the difference of the composite zonal wind between the high and low ZI groups (Fig. 4c lower panel) and the correlation map (Fig. 12). This suggests that the tropospheric ZI in late winter is closely related to the stratospheric zonal-mean zonal wind in mid-winter.

The vertical wave activity flux in late winter also agrees well with ASH's result of a vertical wavenumber $1 \mathrm{EP}$ flux only in regions $\mathrm{B}$ and $\mathrm{C}$. In these regions, the strong stratospheric flux is seen only in AS when high ZI connected with the relatively weak tropospheric flux occurs (Fig. 9). It is suggested that the zonal wind and QSPW variations in late winter undergo a different process from that in early and mid-winter through coupling with the stratosphere.

\section{Concluding remarks}

We studied three-dimensional structures of quasistationary planetary waves (QSPWs) for two groups in which high ZI (typically a double-jet) and low ZI (or a single-jet) occur in the $\mathrm{SH}$ troposphere for three seasons in early winter (April and May), midwinter (June and July) and late winter (August and September). There is a similarity among the horizontal structures for the three seasons. The difference of horizontal structure between the two groups has basically a zonal wavenumber 3 (and wave 4) pattern caused by the changes in amplitude in the eastern hemisphere and phase in the western hemisphere, but a meridional wavetrain in the Pacific Ocean-South America region is dominant in early winter.

The relationship between the wave structures and the zonal wind profiles has been studied by various methods. The stationary wave activity flux diagnostic reveals the clear difference of the meridional QSPW propagation between the two groups, which is consistent with the change in the refractive index. The EP flux divergence analysis suggests the important contribution of both of the QSPWs and high-frequency eddies in forcing the ZI variation. Further studies are needed to link these results obtained from the different viewpoints to each other and hence to clarify the mechanism of the wavemean flow interaction.

The QSPWs are basically barotropic in the troposphere and possess similar features throughout winter. In the stratosphere, on the other hand, the baroclinicity increases in late winter, which results in a maximum amplitude. Intense stratospheric QSPW activity flux occurs in the Indian Ocean-Australia region in late winter for the high ZI group despite of the weaker tropospheric flux, 
which is linked to the SSH's stratospheric interannual variability of zonal-mean zonal wind. Stratospheric wave activity in early and mid-winter is most affected by tropospheric activity between the Pacific Ocean and South America.

Seasonal evolution of the horizontal structure was also studied: There is a qualitative difference in the seasonal evolutions of the PC index between the ASH's typical DS and SD years. It is suggested that the wave activity flux is stronger in SD years than in DS years throughout winter.

\section{Acknowledgments}

We would like to thank Professor J.P. Matthews for his careful reading of this paper to improve the draft. Thanks are also due to the anonymous reviewers for their valuable comments. The GFDDENNOU Library was used for graphical output.

\section{Appendix}

\section{Total steady wavenumber}

Hoskins and Karoly (1981) gave a simple theory on the horizontal propagation of Rossby waves. Following James (1988) who applied their theory to a SH circulation, we interpreted the result obtained in Fig. 6 . Here, the procedure is briefly described. The starting point is the barotropic vorticity equation in the absence of any forcing. By assuming a solution of the form proportional to $e^{i(k x+l y-\omega t)}$ in the linearized vorticity equation on a Mercator projection, a dispersion relation is obtained. For stationary waves, $\omega=0$ and the meridional wavenumber $l$ is represented as a function of the zonal wavenumber $k$ and the total steady wavenumber $K_{s}$ as follows:

$$
l^{2}=K_{s}^{2}-k^{2}=\beta_{M} /[u]-k^{2},
$$

where $\beta_{M}$ is the vorticity gradient on the Mercator map and $[u]$ is zonal-mean zonal wind. The total wavenumber $K_{s}$ corresponds to the refractive index in this framework. Propagation is possible only for waves that satisfy the condition, $K_{s}^{2}>k^{2}$, and disturbances are evanescent meridionally if the meridional wavenumber $l$ is imaginary $\left(l^{2}<0\right)$.

We apply this to the observed zonal-mean zonal wind fields. As typical examples, we show the latitudinal profiles of the zonal-mean zonal wind $[u]$ and the corresponding total steady wavenumber $K_{s}$ for September in 1981 (the case of a single-jet) and 1984 (the case of a double-jet) in Fig. 13. Planetary waves can not propagate meridionally around $45^{\circ} \mathrm{S}$ where the zonal-mean zonal wind is minimum in 1984. This is consistent with Fig. 6 because the strong meridional planetary wave activity flux from the subtropics is observed only for the low ZI group with a single-jet structure. At latitudes higher than $60^{\circ} \mathrm{S}$, planetary waves could not propagate in 1981 with a single-jet structure, which agrees well with the strong fluxes from the polar regions only for the high ZI group with the double-jet structure. Although this is a simple and idealized theory, this result suggests a possibility that the horizontal structures of planetary waves in Fig. 3 are a response to the zonal wind profile.

\section{References}

Aoki, H., M. Shiotani and I. Hirota, 1996: Interannual variability of the tropospheric circulation and its relation to the stratosphere in the southern hemisphere. J. Meteor. Soc. Japan, 74, 509-523.

Blackmon, M.L., 1976: A climatological spectral study of the $500 \mathrm{mb}$ geopotential height of the northern hemisphere. J. Atmos. Sci., 33, 1607-1623.

Hirota, I., T. Hirooka and M. Shiotani, 1983: Upper stratospheric circulations in the two hemispheres observed by satellites. Quart. J. Roy. Meteor. Soc., 109, 443-454.

Hoskins, B.J. and D.J. Karoly, 1981: The steady linear response of a spherical atmosphere to thermal and orographic forcing. J. Atmos. Sci., 38, 1179-1196.

James, I. N., 1988: On the forcing of planetary-scale Rossby waves by Antarctica. Quart. J. Roy. Meteor. Soc., 114, 619-637.

Kalnay, E., M. Kanamitsu, R. Kistler, W. Collins, D. Deaven, L. Gandin, M. Iredell, S. Saha, G. White, J. Woollen, Y. Zhu, M. Chelliah, W. Ebisuzaki, W. Higgins, J. Janowiak, K. C. Mo, C. Ropelewski, J. Wang, A. Leetmaa, R. Reynolds, R. Jenne and D. Joseph, 1996: The NCEP/NCAR 40-year reanalysis project. Bull. Amer. Meteor. Soc., 77, 437-471.

Karoly, D. J., 1990: The role of transient eddies in low-frequency zonal variations in the southern hemisphere circulation. Tellus, 42A, 41-50.

Karoly, D.J., R.A. Plumb and M. Ting, 1989: Examples of the horizontal propagation of quasi-stationary waves. J. Atmos. Sci., 46, 2802-2811.

Kidson, J.W., 1988: Interannual variations in the southern hemisphere circulation. J. Climate, 1, 11771198.

Mechoso C.R., D.L. Hartmann and J.D. Farrara, 1985: Climatology and interannual variability of wave, mean-flow interaction in the southern hemisphere. J. Atmos. Sci., 42, 2189-2206.

Mo, K.C. and G.H. White, 1985: Teleconnections in the southern hemisphere. Mon. Wea. Rev., 113, 22-37.

North, G.R., T.L. Bell, R.F. Cahalan and F.J. Moeng, 1982: Sampling errors in the estimation of empirical orthogonal functions. Mon. Wea. Rev., 110, 699706.

Plumb, R.A., 1985: On the three-dimensional propagation of stationary waves. J. Atmos. Sci., 42, 217229.

Quintanar, A.I. and C.R. Mechoso, 1995a: Quasistationary waves in the southern hemisphere. Part I: observation data. J. Climate, 8, 2659-2672.

Quintanar, A.I. and C.R. Mechoso, 1995b: Quasistationary waves in the southern hemisphere. Part II: generation mechanisms. J. Climate, 8, 26732690 . 
Randel, W.J., 1988: The seasonal evolution of planetary waves in the southern hemisphere stratosphere and troposphere. Quart. J. Roy. Meteor. Soc., 114, 1385-1409.

Randel, W.J., 1992: Global atmospheric circulation statistics, 1000-1 mb. NCAR Tech. Note, NCAR/TN-366+STR, 256pp.

Rogers, J.C. and H. van Loon, 1982: Spatial variability of sea level pressure and $500 \mathrm{mb}$ height anomalies over the southern hemisphere. Mon. Wea. Rev., 110, 1375-1392.

Shiotani, M., 1990: Low-frequency variations of the zonal mean state of the southern hemisphere troposphere. J. Meteor. Soc. Japan, 68, 461-471.

Shiotani, M. and I. Hirota, 1985: Planetary wave-mean flow interaction in the stratosphere: a comparison between northern and southern hemispheres. Quart.
J. Roy. Meteor. Soc., 111, 309-334.

Shiotani, M., N. Shimoda and I. Hirota, 1993: Interannual variability of the stratospheric circulation in the southern hemisphere. Quart. J. Roy. Meteor. Soc., 119, 531-546.

Trenberth, K.E., 1980: Planetary waves at $500 \mathrm{mb}$ in the southern hemisphere. Mon. Wea. Rev., 108, 13781389.

Watterson, I.G. and I.N. James, 1992: Baroclinic waves propagating from a high-latitude source. Quart. J. Roy. Meteor. Soc., 118, 23-50.

Yoden, S., M. Shiotani and I. Hirota, 1987: Multiple planetary flow regimes in the southern hemisphere. J. Meteor. Soc. Japan, 65, 571-586.

Yu, J.-Y. and D.L. Hartmann, 1993: Zonal flow vacillation and eddy forcing in a simple GCM of the atmosphere. J. Atmos. Sci., 50, 3244-3259.

\section{南半球対流圏における準定常惑星規模波動}

\section{青木博松 1 廣田 勇}

(京都大学大学院理学研究科地球物理学教室)

$\mathrm{NCEP} / \mathrm{NCAR}$ 再解析データ 17 年分 (1979-1995) を用いて、Aoki et al. (1996) が示した南半球冬季対 流圈東西風変動 (単一ジェット構造と二重構造の間の変動)に関連して見られる準定常惑星規模波動の立体 構造とその振舞いについて調べた。

この 2 種類のジェット構造間の変動に関連した準定常惑星規模波動の変動の特徵を把握するため、300 hPa におけるジオポテンシャル高度場を用いて経験的直交関数 (EOF) 解析を試みた。その波動は東西波数 3 または 4 型の水平構造を持ち、主に、東半球での振幅、西半球での位相の変化を示している。波活動度フ ラックス診断法によりその波動の特徴を更に解析してみると、単一ジェット時には亜熱帯から中緯度、二重 ジェット時には極域から中緯度への伝播が見られ、それが水平構造に違いをもたらすことがわかった。成 層圏における波活動度は、初冬と真冬には単一ジェット時 (太平洋〜南アメリカ域)、晚冬には二重ジェツ ト時 (インド洋〜オーストラリア域)により大きくなっている。

準定常惑星規模波動の活動と帯状平均東西風構造との関係について理解を深めるために、EPフラックス の発散を計算した。波動全体による水平発散が 2 種類のジェット構造の違いを維持するのに決定的な役割を 果たしているが、それは、主に、短周期擾乱によるものであり、準定常惑星規模波動の寄与はむしろ小さ い。しかし、水平発散と鉛直発散を合わせて考えた場合、 $40^{\circ} \mathrm{S}$ 付近では準定常惑星規模波動の寄与は小さ いが、 $60^{\circ} \mathrm{S}$ 付近では帯状平均東西風の偏差を維持するのには重要な役割を果たしていることがわかった。

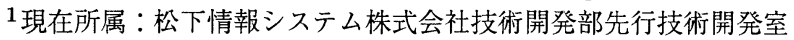

